\begin{tabular}{|c|c|c|c|}
\hline $\begin{array}{c}\text { RESEARCH } \\
\text { ARTICLE }\end{array}$ & $\begin{array}{r}\text { ADVANCE RESEARCH JOURNAL OF } \\
\text { Volume } 5 \text { | Issue } 2 \text { | December, 2014 | 119-125 }\end{array}$ & $\begin{array}{l}\text { SOCIAL SCIENCE } \\
\text { e ISSN-2231-6418 }\end{array}$ & \\
\hline $0=$ & DOI: 10.15740/HAS/ARJSS/5.2/119-125 & Visit us : www.researchjournal.co.in & \\
\hline
\end{tabular}

\title{
Inculcating nutrition knowledge through education intervention
}

Preety* and Uma S. Hiremath

Department of Extension and Communication Management, College of Rural Home Science, University of Agricultural Sciences, DHARWAD (KARNATAKA) INDIA

(Email: preetykalash@gmail.com)

\section{ARTICLE INFO :}

Received : 02.06 .2014

Revised : 15.10 .2014

Accepted : 01.11 .2014

KEY WORDS :

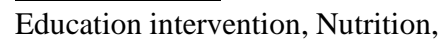
Knowledge

HOW TO CITE THIS ARTICLE :

Preety and Hiremath, Uma S. (2014). Inculcating nutrition knowledge through education intervention. Adv. Res. J. Soc. Sci., 5 (2) : 119125.

*Author for correspondence

\begin{abstract}
Nutrition education is a method where the messages related to nutrition is transmitted to bring about a desirable change in the target group school students are vulnerable to learning and are more receptive to changes. Hence, the study was conducted to know the impact of education intervention on nutrition. Seventy five early adolescent rural boys and girls of high school of Dharwad district of Karnataka were purposively selected for the study. The lessons were prepared and delivered on nutrition on selected five topics including food, balanced diet, water and dietary fibre, healthy cooking methods and minor millets. The results revealed that chapter wise knowledge gain of respondents before and after education intervention was maximum in water and dietary fibre $(26.67 \%)$ followed by minor millets $(22.67 \%)$, healthy cooking methods (21.34\%), food (20.00\%) and balanced diet (17.33\%). The overall values of both the classes depicted 97.33 per cent of respondents in high knowledge level and 1.33 per cent in medium and low each after the education intervention. The change in the mean scores before and after the education intervention proved the considerable impact of education intervention. A significant relationship of knowledge of students and standards (8 and 9) was reported. Moreover, the pretest score was found to be significantly related to the post test scores. Acquiring nutrition knowledge and putting it into practice from early adolescent age can help to uplift the nutritional status of the students to a considerable extent. The positive impact of education intervention denotes the effectiveness of such education intervention programmes and suggests implication of more such programmes in the rural areas.
\end{abstract}

